\title{
KURS RUPIAH, INDEKS NIKKEI 225, BI RATE, DAN PENGARUHNYA TERHADAP STOCK EXCHANGE INDEKS HARGA SAHAM GABUNGAN (IHSG) PERIODE TAHUN 2018-2020
}

\author{
Andini Nurwulandari \\ Universitas Nasional, Jakarta \\ Email: andinmanajemen@gmail.com
}

\begin{abstract}
Abstrak
Pertumbuhan Produk Domestik Bruto (PDB) merupakan indikator konstruktif dan sebaliknya. Kenaikan PDB mempengaruhi daya beli warga secara positif. Oleh karena itu, hal itu akan meningkatkan permintaan akan komoditas tersebut. Lonjakan pasar barang meningkatkan pendapatan perusahaan dan juga dapat meningkatkan harga saham. Penelitian ini mengguanakan metode kuantitatif dengan pendekatan analisis deskriptif. Analisis tersebut dirancang untuk menguji pengaruhnya terhadap indeks harga saham gabungan dengan menggunakan data time series Januari 2018 hingga Desember 2020 dari nilai tukar Rupiah, Indeks Nikkei 225, dan BI Rate. Sistem Indeks Harga Saham Campuran merupakan regresi linier berganda untuk mengenali pengaruh signifikan BI, Rupiah dan Nikkei 225. Hasil pengujian menunjukkan bahwa BI rate memiliki pengaruh yang menguntungkan dan esensial terhadap IHGS dan Rupiah exchange value. Sementara itu, Indeks Harga Saham Gabungan tidak terpengaruh oleh Indeks Nikkei 225.
\end{abstract}

Kata Kunci: IHGS, BI Rate, Kurs Rupiah, Indeks Nikkei225.

\begin{abstract}
Gross Domestic Product (GDP) growth is a constructive indicator and vice versa. A rise in GDP affects the buying power of citizens positively. It will therefore raise demand for the commodity. A surge in the market for goods raises the firm's earnings and may also increase the stock price. The analysis was designed to examine the impact on composite stock price index using data from time series from January 2018 to December 2020 of Rupiah Exchange rate, Nikkei 225 Index, and BI Rate. Multiple linear regression is used in the mixed Stock Price Index scheme to identify the relevant influence of BI on the Rupiah and Nikkei 225. The test results show that the BI rate has a significant positive effect on the Rupiah exchange rate for the composite stock pricing index. Meanwhile, the Nikkei 225 Index has no impact on the Composite Stock Price Index.
\end{abstract}

Keywords: Composite Stock Price Index, BI Rate, Rupiah Exchange Rate, Nikkei225 Index.

\section{A. PENDAHULUAN}

BI sebagai pengendali strategis moneter menetapkan kebijakan keuangan yang sehat bagi perekonomian nasional, keputusan yang diambil di bank Indonesia melalui kebijakan BI tidak berhasil serta tidak efisien (Aditya, Sinaga \& Maulana, 2018). Bank Indonesia perlu, seperti menentukan nilai tukar SBI, bisa menghitung pergerakan dana. Selain itu, Pemerintah juga berperan penting dalam memantau laju inflasi, termasuk dengan menyusun strategi pengeluaran untuk belanja negara (Adnyana \& Nurwulandari, 2020). Di sisi lain, sektor luar negeri, termasuk penjualan ekspor, berperan penting dalam mengendalikan inflasi. Dengan 
demikian, dapat mengatur laju pertumbuhan inflasi atau bahkan menghindari kasus tersebut (Albab, 2015). Oleh karena itu, inflasi pemerintah dan swasta tidak boleh dilupakan, karena dapat berdampak cukup luas, untuk mencapai dan menopang stabilitas harga serta kerja sama dan aliansi yang berkelanjutan yang dibutuhkan oleh seluruh pelaku ekonomi di Bank Indonesia (Anggriana \& Paramita, 2020). Inflasi yang lebih tinggi itu signifikan karena telah efek ekonomi yang dapat menyebabkan ketidakstabilan, pertumbuhan ekonomi yang lemah dan meningkatnya pengangguran. Manajemen inflasi yang stabil juga sangat penting (Apriansyah, Prabawa \& Kamaludin, 2014).

Pasar Uang Antar Bank akan bereaksi terhadap kenaikan suku bunga SBI, sedangkan jawaban atas suku bunga tabungan akan diberikan kemudian. Semakin tinggi jumlah uang di masyarakat, semakin tinggi preminya (Husnul, Hidayat \& Sulasmiyati, 2017). Sementara itu, investasi bisnis riil sedang menurun sehingga produktivitas menurun (dengan asumsi permintaan konstan) (Dewi, 2017). Tingkat pasar (inflasi tinggi) sesuai dengan tingkat yang lebih tinggi sehingga tingkat inflasi merupakan hubungan yang baik (Kurniawan, 2017). Inflasi yang mendorong biaya, di mana inflasi mempengaruhi ekonomi yang berkembang pesat dengan tingkat pengangguran yang rendah, menyebabkan inflasi sebagai akibat dari kenaikan suku bunga. Jika perusahaan terus menghadapi permintaan yang meningkat, pasokan akan meningkat.

Di beberapa perusahaan di Indonesia, pergerakan indeks harga saham patokan relatif berfluktuasi dari tahun sebelumnya ke tahun selanjutnya. Sebabnya adalah pergeseran harga makroekonomi dan logam mulia (emas) (Mawaddah \& Nurwulandari, 2019). Perubahan tingkat indeks harga saham menunjukkan bagaimana orang berinvestasi dalam uang mereka dari sudut pandang ekonomi. Namun menurut ekonom, pengaruh yang berbeda baik secara internal maupun eksternal akan mempengaruhi pergerakan IHSG (Melati \& Nurwulandari, 2019). Pertimbangan internal dapat ditentukan oleh aktivitas negara yang melibatkan berbagai variabel. Bunga dan nilai logam mulia (emas) tampaknya merupakan produk dari pengaruh luar negeri. Hal ini menyebabkan tingkat volatilitas IHSG per tahun berfluktuasi (Noer, Saribanon \& Nurwulandari, 2017). Situasi ini menunjukkan bahwa pola valuasi IHSG tidak dapat diprediksi karena berbagai pengaruh makroekonomi (Sihombing, 2014). Seiring dengan pola pergerakan dan permasalahannya menjelaskan secara detail variabel-variabel yang menjadi permasalahan dengan dampak dari berbagai faktor. Pola inflasi menunjukkan kondisi perekonomian yang fluktuatif. tingkat pertumbuhan meningkat. Keadaan ini menunjukkan bahwa situasi tersebut dapat dilihat sebagai masalah dalam jangka panjang (Silim, 2013). Dalam analisis kemajuan ekonomi suatu negara, aktivitas pendapatan merupakan prediktor yang signifikan. Terciptanya pertumbuhan bisnis yang mengarah pada peningkatan barang \& jasa yang disediakan oleh masyarakat dapat dipandang sebagai pertumbuhan ekonomi (Siregar \& Bachtiar, 2010).

Penurunan pendapatan telah menyebabkan penurunan minat pasar. Ini mempengaruhi tren indeks harga komposit (Swastika, 2013). Investor kemudian berpikir bahwa investasi mereka harus dialihkan ke emas daripada bertaruh di pasar saham. Rendahnya minat investasi pasar modal dan perilaku jual pembeli menyebabkan penurunan nilai saham reksa dana di pasar modal (Subiantoro \& Sulasmiyati, 2018).

Sebagai prediktor pertumbuhan ekonomi yang mempengaruhi indeks saham, harga Produk Domestik Bruto (PDB) yang mengukur pendapatan negara (Winarto, 2015). Riset 
beberapa ekonom menunjukkan bahwa GDP berdampak besar pada volatilitas indeks harga saham. Jika harga beli produk ditetapkan, maka biaya produksi secara alami akan meningkat, dan berdampak pada penurunan keuntungan (Witjaksono, 2010). Investor akan bereaksi negatif terhadap tanda-tanda penurunan pendapatan yang berujung pada penurunan nilai saham akibat kegagalan perusahaan menghasilkan dividen yang optimal. Inflasi memiliki pengaruh penting terhadap volatilitas IHSG. Hal tersebut ternyata berdampak besar terhadap pergerakan IHSG terhadap nilai tukar rupiah.

\section{B. METODE}

Penelitian ini berjenis kuantitatif dengan pendekatan analisis-deskriptif yang bersifat kausal. Sumber data penelitian berua data sekunder. Sedangkan observasi ini menggunakan data runtun waktu (Data Kurs, dan Data Indeks Nikkei 225). Teknik Pengumpulan data yang digunakan melalui dokumentasi dari data-data pada web resmi BI dan finance yahoo.

\section{HASIL DAN PEMBAHASAN}

\section{Index Harga Saham Gabungan (IHSG)}

Analisis ini menggunakan data indeks data campuran set bulanan situs web BI. Tabel indeks harga gabungan untuk 2018-2020 disajikan di bawah ini:

Tabel 1 Data IHSG Tahun 2018-2020

\begin{tabular}{|l|c|c|c|}
\hline \multicolumn{1}{|c|}{ Bulan } & $\mathbf{2 0 1 8}$ & $\mathbf{2 0 1 9}$ & $\mathbf{2 0 2 0}$ \\
\hline Januari & $3.327,221$ & $4.378,348$ & $5.515,036$ \\
\hline Februari & $3.531,083$ & $4.540,123$ & $5.880,715$ \\
\hline Maret & $3.859,244$ & $4.5417,521$ & $5.746,337$ \\
\hline April & $3.852,021$ & $4.075,383$ & $5.739,549$ \\
\hline Mei & $3.982,822$ & $4.115,325$ & $5.897,827$ \\
\hline Juni & $3.787,526$ & $5.811,523$ & $6.036,489$ \\
\hline Juli & $4.128,562$ & $5.703,277$ & $6.314,728$ \\
\hline Agustus & $4.325,281$ & $5.803,483$ & $6.474,823$ \\
\hline September & $4.231,232$ & $5.322,884$ & $6.454,564$ \\
\hline Oktober & $4.108,286$ & $5.545,058$ & $6.523,492$ \\
\hline November & $4.128,824$ & $5.556,237$ & $6.257,810$ \\
\hline Desember & $4.335,829$ & $5.693,782$ & $6.380,721$ \\
\hline
\end{tabular}

Sumber: www.finance.yahoo.com (data diolah)

Berdasarkan Tabel 1 IHGS memperoleh nilai minimum sebesar 3.227,221 poin pada bulan januari 2018 dan mendapat nilai maksimum sebesar $6.523,492$ poin pada bulan Oktober 2020 .

\section{BI Rate}

Penelitian ini menggunakan data interest rate bulanan BI pada website BI. Berikut tabel interest rate Bank Indonesia 2018-2020.

Tabel 2 Data Suku Bunga BI Rate 2018-2021

\begin{tabular}{|l|c|c|c|}
\hline \multicolumn{1}{|c|}{ Bulan } & $\mathbf{2 0 1 8}$ & $\mathbf{2 0 1 9}$ & $\mathbf{2 0 2 0}$ \\
\hline Januari & $8,50 \%$ & $8,75 \%$ & $8,25 \%$ \\
\hline Februari & $8,50 \%$ & $8,50 \%$ & $8,00 \%$ \\
\hline Maret & $8,50 \%$ & $8,50 \%$ & $7,75 \%$ \\
\hline
\end{tabular}


ARTIKEL

\begin{tabular}{|l|l|l|l|} 
April & $8,50 \%$ & $8,50 \%$ & $7,75 \%$ \\
\hline Mei & $8,50 \%$ & $8,50 \%$ & $7,75 \%$ \\
\hline Juni & $8,50 \%$ & $8,50 \%$ & $7,50 \%$ \\
\hline Juli & $8,50 \%$ & $8,50 \%$ & $7,50 \%$ \\
\hline Agustus & $8,50 \%$ & $8,50 \%$ & $6,25 \%$ \\
\hline September & $8,50 \%$ & $8,50 \%$ & $6,00 \%$ \\
\hline Oktober & $8,50 \%$ & $8,50 \%$ & $5,75 \%$ \\
\hline November & $8,75 \%$ & $8,50 \%$ & $5,75 \%$ \\
\hline Desember & $8,75 \%$ & $8,50 \%$ & $5,75 \%$ \\
\hline
\end{tabular}

Sumber: www.bi.go.id (data diolah)

Berdasarkan tabel 2 BI Rate memperoleh nilai minimum sebesar 6,00\% pada bulan September 2020 dan mendapatkan nilai maksimum sebesar $8,75 \%$ pada bulan November 2018 sampai dengan Januari 2019.

\section{Kurs}

Analisis ini menggunakan data kurs tengah per bulan yang disajikan pada website Bank Indonesia. Berikut ini tabel Kurs tengah tahun 2018-2020:

Tabel 3 Data Kurs Tengah Tahun 2018-2020

\begin{tabular}{|l|c|c|c|}
\hline \multicolumn{1}{|c|}{ Bulan } & $\mathbf{2 0 1 8}$ & $\mathbf{2 0 1 9}$ & $\mathbf{2 0 2 0}$ \\
\hline Januari & $\mathrm{Rp} 13.189,65$ & $\mathrm{Rp} 13.589,10$ & $\mathrm{Rp} 14.899,60$ \\
\hline Februari & $\mathrm{Rp} 12.945,10$ & $\mathrm{Rp} 13.759,84$ & $\mathrm{Rp} 14.5125,70$ \\
\hline Maret & $\mathrm{Rp} 12.437,05$ & $\mathrm{Rp} 14.056,82$ & $\mathrm{Rp} 14.183,14$ \\
\hline April & $\mathrm{Rp} 12.445,75$ & $\mathrm{Rp} 14.957,84$ & $\mathrm{Rp} 14.189,86$ \\
\hline Mei & $\mathrm{Rp} 12.535,94$ & $\mathrm{Rp} 14.150,53$ & $\mathrm{Rp} 14.429,65$ \\
\hline Juni & $\mathrm{Rp} 12.882,62$ & $\mathrm{Rp} 14.323,24$ & $\mathrm{Rp} 14.365,05$ \\
\hline Juli & $\mathrm{Rp} 12.699,06$ & $\mathrm{Rp} 14.384,79$ & $\mathrm{Rp} 14.128,82$ \\
\hline Agustus & $\mathrm{Rp} 12.716,67$ & $\mathrm{Rp} 14.791,75$ & $\mathrm{Rp} 14.175,00$ \\
\hline September & $\mathrm{Rp} 12.880,77$ & $\mathrm{Rp} 15.386,10$ & $\mathrm{Rp} 14.128,24$ \\
\hline Oktober & $\mathrm{Rp} 13.154,87$ & $\mathrm{Rp} 15.785,86$ & $\mathrm{Rp} 14.027,24$ \\
\hline November & $\mathrm{Rp} 13.168,30$ & $\mathrm{Rp} 14.682,57$ & $\mathrm{Rp} 14.320,50$ \\
\hline Desember & $\mathrm{Rp} 13.448,29$ & $\mathrm{Rp} 14.864,60$ & $\mathrm{Rp} 14.427,67$ \\
\hline
\end{tabular}

Sumber: www.bi.go.id (data diolah)

Berdasarkan Tabel 3 Kurs tengah memperoleh nilai minimum sebesar Rp. 12.437,05 pada bulan Maret 2018 dan memperoleh nilai maksimum Rp. 15.785,86 pada bulan Oktober 2019.

\section{Nikkei 225 Index}

Analisis ini menggunakan data Indeks Nikkei 225 per bulan yang disajikan pada website Yahoo Finance tahun 2018-2020:

Tabel 4 Indeks Nikkei 225 Tahun 2018-2020

\begin{tabular}{|l|c|c|c|}
\hline \multicolumn{1}{|c|}{ Bulan } & $\mathbf{2 0 1 9}$ & $\mathbf{2 0 1 9}$ & $\mathbf{2 0 2 0}$ \\
\hline Januari & $18.528,30$ & $20.051,34$ & $24.088,29$ \\
\hline Februari & $17.036,76$ & $20.128,99$ & $23.078,24$ \\
\hline Maret & $17.768,67$ & $19.919,26$ & $22.464,30$ \\
\hline April & $17.676,05$ & $20.186,74$ & $23.477,87$ \\
\hline Mei & $18.244,98$ & $20.660,57$ & $23.211,82$ \\
\hline Juni & $16.585,92$ & $21.043,43$ & $23.314,51$ \\
\hline
\end{tabular}


ARTIKEL

\begin{tabular}{|l|l|l|l|} 
Juli & $17.579,27$ & $20.935,18$ & $23.563,72$ \\
\hline Agustus & $17.897,40$ & $20.656,24$ & $23.875,15$ \\
\hline September & $17.459,84$ & $21.366,28$ & $25.130,04$ \\
\hline Oktober & $18.435,02$ & $23.021,61$ & $22.930,46$ \\
\hline November & $19.318,48$ & $23.734,96$ & $23.361,06$ \\
\hline Desember & $20.134,37$ & $23.774,94$ & $21.024,77$ \\
\hline
\end{tabular}

Sumber: www.finance.yahoo.com_(data diolah)

\section{Analisis Deskriptif}

Minimum nilai sampel, median, mean, dan perbedaan normal untuk masing-masing variabel yang dipertimbangkan terlihat untuk analisis statistik deskriptif. Indeks pasar saham agregat, BI rate, mata uang dan Nikkei 225 index adalah variabel yang digunakan untuk analisis ini. Analisis dilakukan dengan tabel berikut di Eviews versi 9:

Tabel 5 Analisis Statistik Deskriptif

\begin{tabular}{|c|c|c|c|c|}
\hline & Y_IHSG & X1_SB & X2_KURS & X3_NKK25 \\
\hline Mean & 5452.187 & 7.154923 & 14245.85 & 18963.18 \\
\hline Median & 5382.764 & 8.500030 & 12342.33 & 19147.66 \\
\hline Maximum & 6714.641 & 8.840001 & 16168.97 & 25468.41 \\
\hline Minimum & 5423.890 & 5.360001 & 11528.05 & 16678.75 \\
\hline Std. Dev. & 593.4589 & 2.546228 & 957.9787 & 3293.883 \\
\hline Skewness & 0.282772 & -0.290143 & -0.200098 & 0.569659 \\
\hline Kurtosis & 3.276857 & 2.409506 & 3.850327 & 1.963819 \\
\hline & & & & \\
\hline Jarque-Bera & 1.890725 & 8.477889 & 0.809553 & 8.307788 \\
\hline Probability & 0.482435 & 0.033782 & 0.434624 & 0.023237 \\
\hline & & & & \\
\hline Sum & 332082.2 & 379.7600 & 794240.8 & 1181747. \\
\hline Sum Sq. Dev. & 20034731 & 107.8126 & 43520225 & $6.36 \mathrm{E}+08$ \\
\hline \multicolumn{2}{|c|}{} & 60 & & 60 \\
\hline Observations & 60 & 6 & & 6 \\
\hline
\end{tabular}

Sumber: Output Eviews v9

Tabel 5 menunjukkan nilai minimum 5423.890 poin dan nilai median 5382.764 poin dengan nilai rata-rata 5452.187 poin dan standar deviasi 593.4589 poin. Indeks harga saham gabungan berdasarkan tabel 5 .

BI Rate memperoleh nilai minimum sebesar 5,360001 atau 5,36\%, dan nilai maksimum sebesar 8.840001 atau 8,84\% dengan nilai rata-rata sebesar 7,154923 atau 7,15\%, dan standar deviasi sebesar 2,546228 atau 2,54\%.

Nilai Tukar/Kurs memperoleh nilai minimum sebesar 11528.05, dan nilai maksimum sebesar 25468.41 dengan nilai rata-rata sebesar 14245.85, dan standar deviasi sebesar 957.9787 .

Indeks Nikkei 225 memperoleh nilai minimum sebesar 16678.75 poin, dan nilai maksimum sebesar 24.658 poin dengan nilai rata-rata sebesar 18963.18 poin, dan standar deviasi sebesar 3293.883 .

Transaksi Valuta Asing dimana semua pihak setuju untuk menukar rekening banknya untuk melakukan transaksi (Yuanisa \& Muharam, 2013). Nilai tukar yang mendasarinya disebut dengan Spot (Spot Exchange Rate), sedangkan transaksinya disebut sebagai 
Transaksi Spot (Zabidi \& Haryono, 2018). Kata "langsung" atau "spot" tidak sepenuhnya akurat, karena perdagangan spot biasanya diadakan dua hari setelah penawaran baru diumumkan. Penantian ini terjadi karena sebagian besar transfer bank membutuhkan waktu dua hari kerja untuk diselesaikan (misalnya, dalam bentuk cek).

\section{KESIMPULAN}

Berdasarkan hasil penelitian, dapat disimpilkan bahwa IHGS berdampak negatif signifikan terhadap BI rate yang ditawarkan antar bank. Dalam pengambilan keputusan investasi, investor harus memperhitungkan BI rate. Penurunan IHGS sejalan dengan kenaikan BI rate. Akibatnya, struktur suku bunga dua lapis yang mempengaruhi IHGS mengalami kenaikan. Exchange value berpengaruh negatif dan signifikan terhadap IHGS. Dalam menentukan pilihan investasi, investor harus memperhitungkan nilai tukar Rupiah/USD. Investor dapat memantau komposisi portofolionya seiring dengan perubahan nilai tukar Rupiah/USD. IHGS indeks Nikkei 225 tidak terpengaruh (IHSG). Naik turunnya indeks Nikkei 225, tidak berdampak pada IHGS. Karena Jepang berinvestasi dalam aset riil daripada saham. Di Indonesia, investasi Jepang berfokus pada industri dan pembangunan pabrik.

\section{DAFTAR PUSTAKA}

Aditya, A., Sinaga, B. M., \& Maulana, T. A. (2018). Pengaruh indeks bursa luar negeri, indikator makroekonomi dan krisis ekonomi global terhadap indeks harga saham gabungan di Indonesia. Jurnal Aplikasi Bisnis dan Manajemen (JABM), 4(2), 284284.

Adnyana, I., \& Nurwulandari, A. (2020). Empirical Examination of Intersectoral Linkages Between Tourism and Regional Economy by Using the Social Accounting Matrix. International Journal of Economics \& Business Administration (IJEBA), 8(1), 425-432.

Albab, A. (2015). Pengaruh Indeks Nikkei 225, Dow Jones Industrial Average, BI Rate dan Kurs Dollar Terhadap Indeks Harga Saham Gabungan (IHSG): Studi Kasus Pada IHSG Bursa Efek Indonesia Tahun 2008-2013 (Doctoral dissertation, Universitas Brawijaya).

Anggriana, R. S., \& Paramita, R. S. (2020). Analisis Pengaruh BI Rate, Kurs, Inflasi, Harga Minyak, dan Harga Emas Dunia terhadap Indeks Harga Saham Gabungan Periode 2016-2019. Jurnal Ilmu Manajemen, 8(3), 1085-1098.

Apriansyah, Y., Prabawa, S. A., \& Kamaludin, K. (2014). Analisis Pengaruh Kurs (Usd/Idr), Suku Bunga Sertifikat Bank Indonesia (Sbi), Inflasi Dan Indek Nikkei 225 Terhadap Indeks Harga Saham Gabungan (Ihsg) Di Bursa Efek Indonesia (Bei) Periode Januari 2004-Agustus 2013 (Doctoral dissertation, Universitas Bengkulu).

Dewi, I. G. A. A. O., \& Dewi, I. G. A. A. P. (2017). Corporate social responsibility, green banking, and going concern on banking company in Indonesia stock exchange. International journal of social sciences and humanities, 1(3), 118-134.

Husnul, H. M., Hidayat, R. R., \& Sulasmiyati, S. (2017). Analisis pengaruh inflasi, kurs (IDR/USD), produk domestik bruto dan harga emas dunia terhadap indeks harga 
saham gabungan (studi pada Indonesia periode 2008-2016). Jurnal Administrasi Bisnis, 53(1), 66-74.

Kurniawan, R. (2017). Effect of environmental performance on environmental disclosures of manufacturing, mining and plantation companies listed in Indonesia stock exchange. Arthatama, 1(1), 6-17.

Mawaddah, T., \& Nurwulandari, A. (2019). Pengaruh Indeks KLCI, STI, SET, Dan PSEI (Integrasi Afta) Terhadap IHSG. Oikonomia: Jurnal Manajemen, 14(2).

Melati, M., \& Nurwulandari, A. (2019). Analisis Reaksi Pasar terhadap Stock Split pada Perusahaan Bertumbuh dan Tidak Bertumbuh. Oikonomia: Jurnal Manajemen, 13(2).

Noer, M., Saribanon, N., \& Nurwulandari, A. (2017). Business Model Analysis of Natural Production Forest with Sustainable Forest Management Approach. GeografiaMalaysian Journal of Society and Space, 13(1).

Sihombing, P. (2014). Pengaruh Indeks Saham Global dan Kondisi Makro Indonesia Terhadap Indeks Harga Saham Gabungan Bursa Efek Indonesia. Media Ekonomi, 22(2), 133-150.

Silim, L. (2013). Pengaruh variabel ekonomi makro terhadap indeks harga saham gabungan pada bursa efek indonesia periode 2002-2011. Calyptra, 2(2), 1-18.

Siregar, S. V., \& Bachtiar, Y. (2010). Corporate social reporting: empirical evidence from Indonesia Stock Exchange. International Journal of Islamic and Middle Eastern Finance and Management.

Subiantoro, A. N., Topowijono, T., \& Sulasmiyati, S. (2018). Pengaruh Inflasi, BI Rate, Kurs USD/IDR, Indeks Shcomp, Dan Indeks Nikkei 225 Terhadap Indeks Harga Saham Gabungan (IHSG)(Studi Pada Bursa Efek Indonesia Periode 2015-2017). Jurnal Administrasi Bisnis, 61(3), 198-206.

Swastika, D. L. T. (2013). Corporate governance, firm size, and earning management: Evidence in Indonesia stock exchange.IOSR Journal of Business and Management, 10(4), 77-82.

Winarto, J. (2015). The determinants of manufacturer firm value in Indonesia stock exchange. International Journal of Information, Business and Management, 7(4), 323.

Witjaksono, A. A. (2010). Analisis Pengaruh Tingkat Suku Bunga SBI, Harga Minyak Dunia, Harga Emas Dunia, Kurs Rupiah, Indeks Nikkei 225, dan Indeks Dow Jones terhadap IHSG (studi kasus pada IHSG di BEI selama periode 2000-2009)(Doctoral dissertation, Universitas Diponegoro).

Yuanisa, T., \& Muharam, H. (2013). Analisis Pengaruh BI Rate, Kurs, Inflasi, Indeks Dow Jones, dan Indeks Nikkei 225 Terhadap Indeks Harga Saham Gabungan (IHSG) di BEI Periode 2006.1-2012.12 (Doctoral dissertation, Fakultas Ekonomika dan Bisnis).

Zabidi, I. I., \& Haryono, N. A. (2018). Pengaruh Inflasi, Kurs, Suku Bunga Sbi, Dow Jones, Dan Nikkei 225 Terhadap Indeks Harga Saham Gabungan Pada Bursa Efek Indonesia Periode 2012-2016. Jurnal Ilmu Manajemen (JIM), 6(4). 